\title{
La comunicación interna como herramienta indispensable de la administración de empresas
}

\section{Internal communication as an indispensable tool of business administration \\ Comunicação interna como ferramenta indispensável da administração de empresas}

\author{
Harold P. Oyarvide-Ramírez ${ }^{\text {I }}$ \\ hoyarvide@gmail.com \\ Edwin F. Reyes-Sarria II \\ edwin.f.reyes.s@gmail.com \\ Milton R. Montaño-Colorado III \\ utefacaemilre@gmail.com
}

Recibido: 25 de mayo de $2017 *$ Corregido: 11 de julio de $2017 *$ Aceptado: 18 de septiembre 2017

\footnotetext{
I Doctor en Ciencias Económicas, Magister en Administración de Empresas, Diploma Superior en Práctica Docente Universitaria, Ingeniero Comercial, Licenciado en Administración de Empresas, Docente de la Universidad Técnica de Esmeraldas Luis Vargas Torres, Esmeraldas, Ecuador.

II Magister en Formulación Evaluación y Gestión de Proyectos Sociales y Productivos, Economista, Docente de la Universidad Técnica de Esmeraldas Luis Vargas Torres, Esmeraldas, Ecuador.

III Magister en Administración de Empresas, Diploma Superior en Gestión y Evaluación de Proyectos, Ingeniero Comercial, Docente de la Universidad Técnica de Esmeraldas Luis Vargas Torres, Esmeraldas, Ecuador.
} 
Dom. Cien., ISSN: 2477-8818

Vol. 3, núm. 4, octubre, 2017, pp. 296-309

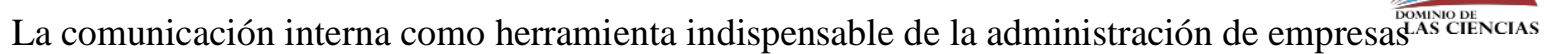

\section{Resumen}

La comunicación interna se convierte, para los gerentes, en una herramienta estratégica que ofrece grandes ventajas empresariales al favorecer la productividad, la competitividad y el éxito empresarial. Es por ello que los administradores de empresas deben dominar los conceptos relacionados con la comunicación interna. De ahí que este trabajo tiene como objetivo abordar los conceptos que entraña la comunicación interna para una mejor administración de empresas. Para ello se expone teóricamente qué se entiende por comunicación interna, los públicos, los mensajes, los canales, las redes, la retroalimentación, los flujos.

Palabras clave: Administración de empresas; comunicación interna; gerentes; mensajes; públicos; canales; redes; flujos; retroalimentación.

\section{Abstract}

Internal communication becomes, for managers, a strategic tool that offers great business advantages to promote productivity, competitiveness and business success. That is why business managers must master the concepts related to internal communication. Hence, this work aims to address the concepts involved in internal communication for better business administration. For this purpose, what is understood by internal communication, the public, messages, channels, networks, feedback, flows is theoretically explained.

Keywords: Business administration; internal communication; managers; messages; public; channels; networks; flows; feedback.

\section{Resumo}

A comunicação interna torna-se, para gerentes, uma ferramenta estratégica que oferece vantagens

comerciais excelentes para promover produtividade, competitividade e sucesso comercial. É por isso que os gerentes de negócios devem dominar os conceitos relacionados à comunicação interna. Assim, este trabalho tem como objetivo abordar os conceitos envolvidos na comunicação interna para uma melhor administração de empresas. Para este propósito, o que é entendido pela comunicação interna, o público, mensagens, canais, redes, feedback, fluxos é explicado teoricamente. 
Dom. Cien., ISSN: 2477-8818

Vol. 3, núm. 4, octubre, 2017, pp. 296-309

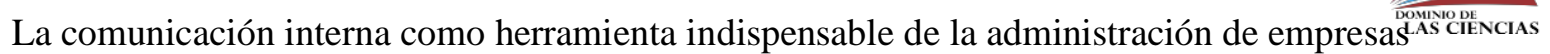

Palavras chave: Administração de empresas; comunicação Interna; gerentes; mensagens; público; canais; redes; fluxos; comentários.

\section{Introducción}

El término comunicación organizacional salía a la luz desde mediados del siglo pasado, pero es en la década del setenta que comienza a confeccionarse su base teórica como disciplina dentro de las ciencias empresariales y sociales, surgiendo un campo de estudio más extenso: la comunicación organizacional o institucional, términos que serán utilizados indistintamente en la presente investigación (Graverán D., 2017).

La comunicación organizacional es el sistema coordinador entre la institución y los públicos, que actúa para facilitar la consecución de los objetivos específicos de ambos y, a través de ellos, contribuir al desarrollo nacional (Muriel M. L., 1980).

La comunicación institucional centra su atención en el análisis, diagnóstico, organización y perfeccionamiento de las complejas variables que conforman los procesos comunicativos en las instituciones, a fin de mejorar la interrelación entre sus miembros, y entre estos y el público externo, lo que conduce a un mejor funcionamiento de la empresa o institución, y al fortalecimiento de su identidad (Trelles I., Comunicación Organizacional: la importancia de su aplicación en Cuba, 2000).

La comunicación organizacional implica una interdependencia entre el ámbito interno y externo. Es aquella actividad capaz de reunir y coordinar a todas las áreas y niveles de la organización en función de su desarrollo y alcance de los objetivos organizacionales. A partir de esta incidencia provee facilidades para la atención e interrelación entre los diferentes públicos desde el análisis, planificación, desarrollo y evaluación de la realidad organizacional. Desde este punto de vista se considera a la comunicación organizacional como: un conjunto de técnicas y actividades encaminadas a facilitar y agilizar el flujo de mensajes que se dan entre los miembros de la organización, o entre la organización y su medio (Peña Ferreiro C., 2011). 
Dom. Cien., ISSN: $2477-8818$

Vol. 3, núm. 4, octubre, 2017, pp. 296-309

La comunicación interna como herramienta indispensable de la administración de empresas ${ }^{\text {AS }}$ (citencias

La Comunicación Organizacional es un "sistema coordinado cuyo objetivo es la armonización de los intereses de la institución con los de sus públicos a fin de facilitar la consecución de sus objetivos específicos y a través de ellos contribuir al bienestar social y al desarrollo nacional, integrando objetivos comunes de áreas como la publicidad, el marketing, las relaciones públicas, la comunicación interna y externa en función de la imagen corporativa” (Trelles Rodríguez I., 2001).

Dentro de la comunicación organizacional se distinguen la comunicación interna y la externa. La comunicación interna se convierte para los gerentes en una herramienta estratégica que permite lograr mayor competitividad, retener a los mejores, identificar a los empleados en una verdadera cultura corporativa, potenciar el sentimiento de pertenencia y el éxito empresarial. Cuando los trabajadores estén informados, si conocen la misión, los valores, la estrategia empresarial, si existe una línea de comunicación eficaz entre los empleados, la dirección y los diferentes departamentos el desempeño de la empresa es superior.

Es un error pensar que la comunicación interna es «un lujo», y algo exclusivo de las grandes empresas y máxime en la etapa que estamos atravesando, que viene marcada por unos resultados un tanto inciertos a todos los niveles. De ahí que se esté convirtiendo en uno de los grandes retos de la administración de empresas del siglo XXI (...) (Muñiz R., 2017).

\section{Desarrollo}

\section{Comunicación interna}

La comunicación interna es una de las principales actividades de la organización, pues mediante esos procesos se coordinan las acciones fundamentales que le dan sentido a la organización, se ejecutan tareas, se realizan cambios, se orientan las conductas interpersonales, y se construyen valores de la cultura organizacional” (Trelles Rodríguez, 2001).

La comunicación interna es el conjunto de funciones y actividades concebidas a partir del proceso de significación y desempeño compartido y desarrollado por los miembros del público interno de la

299 Vol. 3, núm. 4, octubre, 2017, pp. 296-309

Harold P. Oyarvide Ramírez, Edwin F. Reyes Sarria, Milton R. Montaño Colorado 
Dom. Cien., ISSN: 2477-8818

Vol. 3, núm. 4, octubre, 2017, pp. 296-309

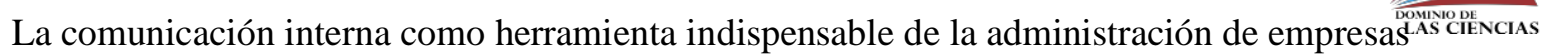

Sucursal con la mediación de los elementos de la cultura y en función los objetivos organizacionales (Peña Ferreiro C., 2011).

Se denomina comunicación interna al conjunto de actividades efectuadas por una organización para la creación y mantenimiento de buenas relaciones con y entre sus miembros a través del uso de diferentes medios de comunicación que los mantenga informados, integrados y motivados para que contribuyan con su trabajo al logro de los objetivos organizacionales, se le denomina comunicación interna (Torres L., 2012).

La comunicación interna incluye las acciones de comunicación que se realizan en las instituciones dirigidas al público interno. Comprende, mediante el empleo de diversos medios y canales, las estrategias y programas de comunicación. Está definida por la interrelación que se pueda lograr entre el personal que compone la organización y su objetivo principal debe ser integrar, comprometer y movilizar al público interno con los objetivos de una institución (Graverán D., 2017).

La comunicación interna es la comunicación dirigida al cliente interno, es decir, al trabajador. Nace como respuesta a las nuevas necesidades de las compañías de motivar a su equipo humano y retener a los mejores en un entorno empresarial donde el cambio es cada vez más rápido. No olvidemos que las empresas son lo que son sus equipos humanos, por ello, motivar es mejorar resultados (Muñiz R., 2017).

La gestión de la comunicación interna persigue optimizar el flujo de información-comunicación y las relaciones humanas entre las diferentes áreas de trabajo, y la dirección y sus trabajadores, para contribuir a la participación, el fortalecimiento de los valores, el buen clima y el trabajo en equipo. De este modo, se logran alcanzar los objetivos organizacionales con el máximo de eficiencia y calidad. La Comunicación Interna debe ser debidamente planificada, implementada y evaluada dentro de la Administración de la Empresa. Esta debe ir encaminada a acciones sistemáticas de promoción y divulgación de actividades que deberán recogerse en planes y estrategias (Laffitte Santiesteban M.E., 2013). 
La principal función que desarrolla en la institución la comunicación interna es apoyar el proyecto empresarial por medio de una coherente y planificada gestión de la comunicación, independientemente de la misión de la organización. Además, permite dar a conocer los objetivos y políticas de la organización y conformar una identidad propia sobre la base de un clima de motivación y cordialidad (Graverán D., 2017).

Cuando la comunicación interna está alineada a la estrategia general de la institución debe cumplir los siguientes objetivos:

- Integrar a todos los trabajadores a los objetivos, normas, políticas y metas de la organización, logrando la motivación de los trabajadores e incrementando el sentido de pertenencia a la organización.

- Establecer un clima social y psicológico positivo en la organización, comunicándose de forma abierta a directivos y trabajadores y fomentando valores positivos en el colectivo laboral.

- Fomentar la participación de los trabajadores en las diversas tareas que se orienten para la realización de los objetivos institucionales.

- Favorecer la creación de una imagen positiva tanto en el público interno como en el externo que sea coherente con su identidad institucional y que conlleve a la obtención de óptimos resultados organizacionales (Grillo G., 2007).

\section{Públicos internos}

Los públicos de una institución en general pueden definirse como: "grupos de personas que se ven afectados por las operaciones de la empresa, que son claves por su capacidad de influir sobre los resultados empresariales y constituyen un elemento central en el entorno competitivo" (Rubalcaba, 2011).

Trelles (2002) clasifica el público interno en: 
Dom. Cien., ISSN: $2477-8818$

Vol. 3, núm. 4, octubre, 2017, pp. 296-309

La comunicación interna como herramienta indispensable de la administración de empresas ${ }^{\text {AS }}$ (citencias

- Directivos o dirigentes de alto nivel: ubicados en la parte superior de la organización, y caracterizados por su responsabilidad en la toma de decisiones, con diferencias en cuanto a su tipo de relación con otros niveles en función de las características de cada empresa en particular.

- Cuadros medios: escalón consecutivo con relación a los anteriores, por lo general, encargado de dirigir los procesos que llevarán a la práctica las decisiones tomadas por el nivel más alto de la organización, grupo más operativo y en relación más directa con la base.

- Base: gran mayoría, trabajadores de la producción o servicios. (Trelles I., 2002).

\section{Flujos}

Los flujos de comunicación no es más que la dirección que toman los procesos comunicativos en una institución, la trayectoria por la cual llegará el mensaje al receptor deseado en relación con el objetivo que persiga (Graverán D., 2017).

Torres (2012), considera que el concepto de flujo se corresponde con la dirección del mensaje y ha sido tradicionalmente dividida en comunicaciones ascendentes, descendentes, horizontales y transversales, dependiendo de quién inicia el mensaje y de quien lo recibe (o se supone que deba recibirlo):

- Descendentes: son aquellos mensajes que fluyen desde los superiores hasta los subordinados.

- Ascendentes: son aquellos mensajes que fluyen desde los subordinados hasta los superiores

- Horizontal: es el intercambio lateral de mensajes entre individuos que se encuentran en el mismo nivel de autoridad dentro de la organización.

- Transversal: es el intercambio de información a través de diferentes niveles de la estructura organizativa, no necesariamente de modo jerárquico ni escalonado, y facilita la interacción entre todos los miembro de la organización, permitiendo la rápida toma de decisiones así como la rápida detección y solución de los problemas (Torres L., 2012). 
Dom. Cien., ISSN: 2477-8818

Vol. 3, núm. 4, octubre, 2017, pp. 296-309

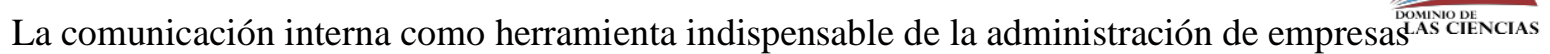

Peña Ferreiro (2011), plantea en relación a los flujos que es el sentido o dirección que toma la comunicación entre los diferentes niveles de la estructura de la organización. Estos presentan diferentes clasificaciones: flujo descendente (recorrido de la comunicación desde la dirección o estructuras superiores hacia los niveles intermedios o la base), flujo ascendente (desde las jerarquías inferiores a las superiores, favoreciendo el diálogo organizacional, la funcionalidad de la retroalimentación y el aprovechamiento de las sugerencias, reflexiones e ideas), flujo horizontal (entre los miembros con niveles similares de jerarquía fuera o dentro de la misma área o departamento) y el flujo transversal (comunicación en todos los sentidos y con implicación en todos los niveles institucionales).

En cuanto a los flujos de comunicación interna, podemos hablar de dos: ascendente, que se realiza desde abajo hacia arriba en el organigrama de la empresa; y descendente, que tiene lugar desde arriba hacia abajo (Muñiz R., 2017).

Los flujos descendentes son usados para organizar y coordinar eficazmente los procesos de trabajo, para promover los atributos de identidad y fortalecer las relaciones con los públicos. Los ascendentes se emplean fundamentalmente como vía de retroalimentación en pos estrechar vínculos entre los directivos y trabajadores, así como entre el público. Los horizontales garantizan la mejor planificación y ejecución de las tareas en un ambiente cooperativo que permita estrechar las relaciones personales y profesionales y contribuir a la resolución de problemas y al consiguiente logro de los objetivos organizacionales (Laffitte Santiesteban M.E., 2013).

\section{Mensajes}

En la literatura se maneja que "el mensaje es el estímulo que la fuente trasmite al receptor; es la idea o sentimiento que se comunica. Los mensajes se componen de símbolos que tienen un significado común para la fuente y el receptor” (Collado, 1997).

Los mensajes contribuyen al hecho de compartir la información entre los diferentes miembros del público en la organización, y los mismos deben presentar una correspondencia tanto con los objetivos institucionales como con las características de los públicos a los que están dirigidos. Es imprescindible 
Dom. Cien., ISSN: 2477-8818

Vol. 3, núm. 4, octubre, 2017, pp. 296-309

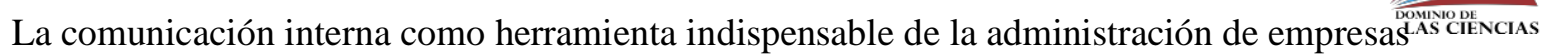

que exista un equilibrio entre los mensajes en toda institución para lograr así una eficiente gestión de la información que circulan en la misma. Los mensajes internos se clasifican en: (Graverán D., 2017)

- Tarea: se refiere a tareas y labores a realizar; el qué y el cuándo de dicha actividad.

- Procedimiento: van a estar relacionados con modos de hacer las cosas, normativas, reglas, métodos que bien pueden ser estándares de calidad, etc.

- Humanos: serían aquellos mensajes de apoyo a los trabajadores, que apelan a lo emotivo, sus sentimientos. Pueden ser también: reconocimientos, estímulos y felicitaciones.

- Estratégicos: directamente vinculados con el conocimiento de la misión, visión, objetivos y planes estratégicos de la entidad.

- Organizativos-coordinadores: sería aquella información que contiene la organización y coordinación del trabajo: interrelación entre las áreas o departamentos, prioridades y la cohesión del colectivo en el tratamiento de las tareas y soluciones a conflictos (quién trabaja, cuándo y dónde lo hace, qué hace en relación con los demás).

- Políticos-motivacionales: aborda temas relacionados con la historia de la institución, así como las personas que han dejado una huella en la entidad y aportes a la Revolución. Pero también contiene información sobre la prestación de servicios con calidad, eficaces y eficientes, altos índices de participación y compromiso (quiénes son, qué pretenden, hacia dónde van, cuál es su historia y tradiciones, quiénes han trabajado en este lugar, qué aportes se han hecho).

- Éticos-morales: normas de comportamiento y disciplina con el propósito de inculcar hábitos, valores, respeto al cumplimiento de las reglas, sentido del deber, colectivismo y solidaridad.

- Pertenencia e implicación: movilización de los trabajadores y dirigentes para incrementar la participación, el enfrentamiento a los inconvenientes y la lucha por la eficiencia (éxitos y fracasos, avances y dificultades, incumplimientos, resultados y experiencias). 
El tipo de mensajes a emplear por públicos, se transmite según sea pertinente en cada caso. Estos, independientemente de su tipo, deben ser reflejo de la cultura e identidad de la Organización y contener información clara, oportuna, precisa y actualizada (Laffitte Santiesteban M.E., 2013).

\section{Canales}

Los canales son considerados como el vehículo que transporta los mensajes de la fuente al receptor, es el eslabón físico entre quien envía el mensaje y el receptor del mismo.

Los canales de comunicación existentes deben ser utilizados adecuadamente según el público al cual se dirija y el tipo de mensaje a transmitir. Los canales formales de comunicación asegurarán el buen funcionamiento de los procesos, a lo interno y externo, para el logro de los objetivos de la organización y los mensajes informales son usados para fortalecer relaciones y crear mayor acercamiento y confianza con los públicos (Laffitte Santiesteban M.E., 2013).

Con relación a la clasificación en el ámbito interno de la organización Peña Ferreiro (2011) hace alusión a diferentes canales, pero que son los flujos de comunicación expuestos por los autores que se citan en este trabajo:

1. Canales verticales descendentes: aquellos que transportan los mensajes desde la dirección o estructuras superiores hacia los niveles intermedios o la base.

2. Verticales ascendentes: aquellos que los trabajadores de los niveles intermedios o la base utilizan para elevar sus mensajes a las estructuras superiores.

3. Canales horizontales: transportan los mensajes entre los niveles similares de jerarquía fuera o dentro de la misma área o departamento.

4. Canales transversales: transportan los mensajes en todos los sentidos y con implicación en todos los niveles institucionales. Estos últimos pueden ser orales o escritos.

5. Canales mixtos los mensajes son transportados en dos o más direcciones. 
Dom. Cien., ISSN: 2477-8818

Vol. 3, núm. 4, octubre, 2017, pp. 296-309

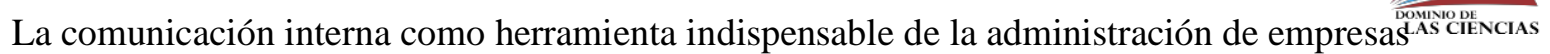

Entonces, muy vinculado a los canales están las redes de comunicación. "Una red de comunicación es el camino que sigue el flujo de mensajes y cada uno de los elementos (departamentos, personas, etc.) por los que pasa, pudiendo estar constituida tan solo por dos personas por unas pocas, o por toda una organización" (Muriel M. L., 1980).

Se habla de redes cuando hay una agrupación de miembros de la organización en función de unas facilidades de comunicación. Las mismas pueden ser formales cuando la viabilidad de la comunicación se alcanza a través de los cauces planificados y establecidos en la organización formalmente; e informales cuando el cauce de la comunicación es más espontáneo (Peña Ferreiro C., 2011).

Las redes formales son aquellas explícitamente señaladas en el organigrama de la institución, que se puede concebir como una descripción diagrámica de la estructura formal de la misma. Las redes informales son aquellas que fluyen sin respetar las líneas jerárquicas o funcionales y obedeciendo más a afinidades personales que a estructuras formales de trabajo (Laffitte Santiesteban M.E., 2013) (Torres L., 2012).

Se pueden clasificar en formales cuando se apegan a la estructura formal de la organización reflejada en el organigrama, e informales cuando el mensaje fluye sin respetar las líneas jerárquicas o funcionales y obedece más a afinidades personales que a estructuras formales de trabajo, y constituyen la respuesta natural a la necesidad de interacción social espontánea que tienen las personas (Graverán D., 2017).

Los canales son el medio o vía por la que circulan los mensajes al interior de una organización. Los canales pueden ser clasificados en: directos (dependen de la capacidad de comunicación directa o cara a cara), indirectos o mediatizados (necesitan algún tipo de tecnología- teléfono, la televisión, la radio, etc., para la producción y difusión de mensajes). Los primeros resultan muy efectivos para percibir de cerca la aceptación o rechazo un mensaje; pues se obtiene de primera mano la manifestación de la comunicación extra verbal (Aduana General de la República de Cuba, 2015). 
Dom. Cien., ISSN: 2477-8818

Vol. 3, núm. 4, octubre, 2017, pp. 296-309

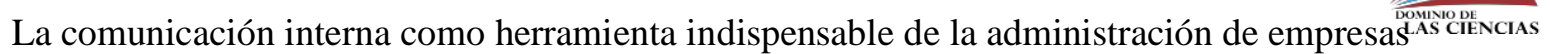

\section{Retroalimentación}

La retroalimentación es un factor primordial que nos permite medir la funcionalidad o no de las acciones de comunicación, además dentro de la empresa da la posibilidad de intercambiar opiniones que vallan en busca de solucionar problemas que puedan existir. La retroalimentación es el "proceso final de la fase intercomunicativa, es la respuesta del receptor, o sea, la reacción o información que se transmite del receptor al emisor que señala cómo se recibió el mensaje y denota qué impacto causó" (Linares P., 2012).

La retroalimentación es el proceso mediante el cual los actores de la comunicación pueden confirmar la efectividad de los mensajes enviados. La atención a la funcionalidad de la retroalimentación contribuye al reconocimiento de los problemas y a la modificación de las respuestas en función de los mismos. Se puede hablar de retroalimentación positiva cuando los efectos logrados ratifican la intención del emisor. Por su parte, la negativa va a constatar efectos sin correspondencia con las intenciones perseguidas y debe ser la de mayor importancia para la organización, debido a la necesidad de lograr siempre una comunicación efectiva (Peña Ferreiro C., 2011).

La búsqueda de retroalimentación será una constante para la proyección con los públicos y la toma de decisiones, para ello deben ser especialmente atendidos los flujos de comunicación ascendente, horizontal y transversal y las redes formales e informales de comunicación (Laffitte Santiesteban M.E., 2013).

Debemos recordar que el diálogo entre la dirección y los trabajadores ha de ser constante. El feedback es fundamental en este tipo de comunicación. Y decimos esto porque todavía existen compañías que confunden la comunicación con la información. La diferencia está muy clara: mientras que esta última consiste en la simple transmisión de mensajes, para que exista comunicación se necesita una respuesta por parte del receptor (Graverán D., 2017). 


\section{Conclusiones}

Cuando se revisa la literatura sobre la administración de empresas aparece de manera reiterada el tema de la comunicación con los empleados, es decir de la importancia de la comunicación interna para el éxito empresarial.

El público interno, los trabajadores o los empleados son un elemento indispensable para el funcionamiento de una organización. En gran medida, se convierten en uno de los ejes fundamentales y probablemente, de la mano con el público externo o clientes; el componente más básico y fundamental. Por lo tanto la gestión de la comunicación interna representa ante todo, una fortaleza para la funcionalidad empresarial y que por tal motivo no debe quedar rezagada del quehacer de la institución.

A su vez al hacer una revisión bibliográfica de este tema aparecen un sinnúmero de manuales que coinciden en los conceptos que explicitan y que son abordados en este trabajo.

\section{Referencias bibliográficas}

Aduana General de la República de Cuba. (2015). Manual de Gestión de la Comunicación Interna.

CIMEX. (2011). Manual de Gestión de la Comunicación Interna.

Collado, C. (1997). La comunicación en las Organizaciones.

Graverán D. (2017). Propuesta de Manual de Gestión de la Comunicación Interna para el Centro Nacional de Biopreparados. Trabajo de Diploma. Facultad de Comunicación. Universidad de la Habana.

Grillo G. (2007). Diagnóstico de Comunicación Interna en el Instituto de Comercio Exterior de Ciudad de La Habana. Tesis en opción al grado de máster en ciencias de la comunicación.

Laffitte Santiesteban M.E. (2013). Manual de la Comunicación Interna de Cubatur. 
Dom. Cien., ISSN: $2477-8818$

Vol. 3, núm. 4, octubre, 2017, pp. 296-309

La comunicación interna como herramienta indispensable de la administración de empresas ${ }^{\text {As }}$ (citencias

Linares P., S. R. (2012). Buenas prácticas. Comunicar e informar. La Habana: Editorial Academia.

Muñiz R. (2017). Marketing en el Siglo XXI.

Muriel M. L., R. G. (1980). Comunicación Institucional: Enfoque social de relaciones públicas. Quito: Editora Andina.

Peña Ferreiro C., B. H. (2011). Manual de Gestión de la Comunicación. Trabajo de Diploma.

Rubalcaba, A. (2011). Plan de Relaciones Públicas 2012. Grupo Empresarial PALCO. Tesis en opción al grado de Máster. Facultad de Comunicación, Universidad de La Habana.

Torres L. (2012). Manual de Gestión de la Comunicación Organizacional.

Trelles I. (2000). Comunicación Organizacional: la importancia de su aplicación en Cuba. Espacio.

Trelles I. (2002). "Modelo de gestión de la comunicación en organizaciones” Tesis de Doctora en Ciencias de la Comunicación. Universidad de La Habana, Facultad de Comunicación.

Trelles Rodríguez I. (2001). Comunicación Organizacional. 